\title{
Para Além de um Corpo Visível: o papel da literatura de ficção científica nas transformações da imagem humana nas redes sociais virtuais
}

\author{
Para Más de un Cuerpo Visible: el papel de la literatura del ficción \\ cientifica en las transformaciones de la imagén humana en las redes \\ sociales virtuales
}

Beyond a Visible Body: the role of science fiction literature in the transformation of the human image on virtual social networks

\author{
Julio Marinho Ferreira ${ }^{1}$
}

\begin{abstract}
Resumo
$\mathrm{O}$ artigo se dispõe a discutir a relação entre um ideário presente na literatura cyberpunk e como a mesma relaciona-se com uma sociedade informacional, principalmente acerca da Internet e da produção de deslocamento de um ambiente real para um ambiente virtual. Dessa forma, com o advento de uma sociedade tecnológica, e o predomínio de uma era informacional das redes de computadores e outros dispositivos, uma sociabilidade mediante esses aparelhos poderia ser vista como a nova forma de interação social. Nisso surge o indivíduo que busca fica o tempo todo conectado, o homo panopticus, o que geraria alguns problemas que pretendemos aqui discutir, como o ato de expor-se e de consumir exposição sem limites, gerando uma espécie de dependência.
\end{abstract}

Palavras-chave: Sociologia Digital; redes sociais; literatura cyberpunk.

\section{Resumen}

El artículo se dispone a discutir la relación entre un ideario presente en la literatura cyberpunk y cómo la misma se relaciona con una sociedad informacional, principalmente acerca de Internet y de la producción de desplazamiento de un ambiente real hacia un ambiente virtual. De esta forma, con el advenimiento de una sociedad tecnológica, y el predominio de una era informacional de las redes de ordenadores y otros dispositivos, una sociabilidad mediante estos aparatos podría ser vista como la nueva forma de interacción social. En esto surge el individuo que busca queda todo el tiempo conectado, el homo panopticus, lo que generaría algunos problemas que pretendemos aqui discutir, como el acto de exponerse y de consumir exposición sin límites, generando una especie de dependencia.

Palabras claves: Sociologia Digital; redes sociales; literatura cyberpunk.

\section{Abstract}

The paper discuss the relation between an idea present in a kind of cyberpunk's literature and how the same links with the information society, close to the Internet and the production of a reallocation between a real and a virtual place. So, with the arrival of a technology society and the dominance of an informational era of computers and others devices, a sociability in that kind of devices could be knew as new form of social interaction. In that society a kind of individual needs to be connected all the time, looking like a "homo

\footnotetext{
${ }^{1}$ Mestrando em Sociologia pela Universidade Federal de Pelotas. E-mail: juliomarferre@hotmail.com.
} 
panopticus", and this brings some problem, such all moment exhibition and a consume of personal exposition among others, treats like a kind of vice.

Key words: Digital Sociology; Social Networks: Cyberpunk Literature.

\section{Introdução}

A sociedade, dentro das obras de ficção científica, é mostrada muitas vezes como um não-lugar, um local deslocado da realidade, um complexo ambiente em que ao mesmo tempo que é dominado pela tecnologia em caráter extremo também é determinado pelo caos em âmbitos gerais. Com isso, provocando descrença e problemas aos seus habitantes, seja frente ao domínio de máquina ou de tecnologia em estados extremos.

A informação, dentro de uma nova configuração social, trouxe acesso e possibilidades sociais variadas, principalmente com o advento da Internet como modeladora e reguladora de relações sociais e afetivas. Os indivíduos, dentro desses contextos, precisariam adaptar-se ao "novo mundo", o lugar do deslocamento de ideias, e ao mesmo tempo, um possibilitador de novas experiências psíquicas e sociais.

O indivíduo, deslocado ou não, pôde produzir e propagar uma outra imagem para si, potencializada pela exposição de uma sociedade tecnológica e também pela sua necessidade de consumir imagens.

Neste trabalho procuramos apresentar a ideia sociológica de indivíduo, dentro da modernidade, e como surgem relações sociais dentro de contextos problemáticos, em que se inserem a visão distópica da literatura cyberpunk. A partir disso, faremos um contraponto para apresentar a sociedade tecnológica e informacional, e o surgimento das redes sociais virtuais como veículos potencializadores de uma lógica em que os indivíduos precisam "ver e serem vistos", dentro de uma ideia de eterna exposição na Internet. Para essa necessidade de expor suas vidas em ambientes virtuais demos o nome de homo panopticus.

Em suma, tendo a Sociologia como "carro-chefe" procuramos dar um aporte mais aberto a uma ideia de sociedade de controle e de exposição, tendo em vista o problema que procuramos discutir, que é o uso de perfis falsos em redes sociais virtuais, os chamados Catfish. Para dessa forma, apresentarmos as possíveis ideias e buscas por trás desses indivíduos enganadores, e também como os mesmos procuram agir.

\section{Das distopias sociais à sociedade informacional}

O indivíduo moderno na ótica de Simmel (1998) foi fundado no pertencimento a um lugar e pela busca de distinção e liberdade - tanto quantitativa quanto qualitativa. Dessa 
maneira, os indivíduos tornados autônomos querem distinguir-se e afirmarem-se entre si. A busca por afirmação seria o cerne do desenvolvimento do indivíduo na modernidade, na sociedade ou na ideia de uma sociedade perfeita podemos observar isso e problematizar o seu contraponto.

Distopia é um termo que significa Lugar Ruim, já que o prefixo Dis, do grego dificuldade, problema ou algo ruim, esse termo tendo surgido na literatura como uma oposição ao termo utopia, que significa Lugar Nenhum. Utopia, ou um não lugar surgiu na literatura no início do século XVI, com o filósofo e figura política inglesa Thomas More (Morus ou Moro), que a criou como forma de crítica social ao momento em que vivia na Inglaterra de Henrique VIII, ou seja, deslocando os indivíduos de sua sociedade para um "não lugar" os mesmos poderiam ser felizes ${ }^{2}$. Uma sociedade distópica seria um ambiente de opressão, de coerção e de eterna vigilância sobre os indivíduos, onde as relações sociais são mantidas sobre a égide de Estados totalitários, não por outro motivo que essa forma literária tenha sua difusão e surgimento na primeira metade do século XX.

Nos textos literários que tratam das distopias tem-se sempre presente o risco que os indivíduos percebem nas falências de valores da modernidade caminhando lado a lado com o surgimento e a afirmação de tecnologias que permitiriam um controle mais invasivo sobre as individualidades. Para Bauman, com a afirmação do Estados-Nação e da ciência como pilares da modernidade que se impõem sobre os indivíduos a partir do século XIX, as relações sociais seguiram um outro rumo. A literatura distópica liga-se a sociologia por tratar de conflitos entre sociedade e os indivíduos e, consequentemente, novas formas de viver-se no social.

O filme Her, é aqui utilizado como um referente ilustrativo para reflexão sociológica é uma história de ficção científica lançada no ano de $2013^{3}$, com direção de Spike Jonze. Essa obra cinematográfica é um retrato "pós" redes sociais virtuais, passando-se em um futuro que em muito parece com os anos 1950. O filme retrata uma distopia muito peculiar, não como na forma de literatura - com seu pessimismo latente - mas sim nas relações entre os indivíduos, que parecem promover um distanciamento, quase um isolamento necessário de ser cultivado socialmente.

Podemos observar que nas redes sociais virtuais por mais que se queiram relações pessoais, o que de fato parece prevalecer são relações do tipo impessoais, sendo estas possibilitadas fundamentalmente pela disposição de não contato, que apenas a virtualidade

\footnotetext{
${ }^{2}$ Outro exemplo relevante de literatura utópica é a obra News of Nowhere (Notícias de lugar nenhum) escrita no final do século XIX por William Morris (1834-1896), escritor, ensaísta e importante figura política do socialismo vitoriano.

${ }^{3}$ Em fevereiro de 2014 no Brasil.
} 
poderia supor, e o filme porta essa ideia de impessoalidade. No decorrer do filme a todo momento temos inúmeras alusões aos desencantamentos sociais com as relações pessoais, inclusive na profissão do protagonista, que é um escritor de cartas de amor para outras pessoas, um fato que comprova a necessidade das pessoas de consumir relações, visto que o amor pode ser um produto fabricado por um escritor e vendido como um objeto. A esse respeito, quando considerava a relação do indivíduo com as formas de vida produzida pela modernidade, Simmel entendia que:

Todas as relações com os outros são, ao fim e ao cabo, apenas estações no caminho em busca de si mesmo, seja porque se sente igual aos outros e sozinho com suas próprias forças, precisando do apoio desse tipo de consciência, seja porque, com a capacidade de encarar a solidão de frente, os outros existem para permitir a cada indivíduo a comparação e a visão da própria singularidade do próprio mundo. (Simmel, 1998, p. 114)

A produção e o consumo de beleza padronizada fazem parte de cultura capitalista que interfere nas relações sociais, na dinâmica do mundo, alterando assim a produção de tudo o que seja socialmente constituído. Como perceberam Deleuze e Guattari:

De modo que tudo é produção: produção de produções, de ações e paixões; produção de registros, de distribuições e marcações; produções de consumo, de volúpias, angústias e dores. Tudo é de tal modo produção que os registros são imediatamente consumidos, consumados, e os consumos são diretamente produzidos (Deleuze, Guattari, 2010, p.14).

A relação entre indivíduo e as formas de sociabilidade promovidas pelas redes sociais virtuais, com bastante frequência, pauta-se por interações nas quais a beleza adquiri um caráter de potência de verdade, de busca e credibilidade. Nesse sentido, pode-se dizer que a sedução pela beleza, que no filme Her, aparece na forma de uma voz feminina, apresenta-se como dispositivo de expressão de novas formas de subjetividade.

As formas de sociabilidade relacionadas ao afeto e à amizade promovem um intercâmbio, que reduziria a imagem bela a uma forma de objeto produzido, que então só surgiria enquanto verdade pela exposição nessa ferramenta tecnológica, e assim, uma reciprocidade latente faz-se presente nessa produção. Nas obras distópicas clássicas do século XX temos o papel do espaço em evidência - seja real ou irreal, há uma relação de mutualidade entre as relações sociais mediadas pela tecnologia. 
Por exemplo, a forma de literatura conhecida como cyberpunk ${ }^{4}$ é um fruto da sociedade informacional a partir do final da década de 1970; um tipo de expressão literária que promove uma visão de mundo, como anteriormente já vista em grandes romances distópicos do século $\mathrm{XX}^{5}$. Alguns de seus marcos fundadores são os romances Neuromancer de William Gibson (1984) e Snow Crash de Neil Stephenson (1992). Como indicado por Richard Miskolci (2016), a relação da sociedade fragmentada pela tecnologia com os indivíduos desencantados ou "perdidos" no meio urbano oferecem um importante referente para a nossa imaginação sociológica, isto é, o seu potencial de criar narrativas sobre novas relações sociais, tendo como protagonistas indivíduos excluídos e não em "esferas à parte".

Ao perceber a relação do indivíduo com o romantismo do século XIX, Simmel entendeu que as vanguardas artísticas fundiram na modernidade as suas ideias culturais. Com isso em mente, entendemos ser possível dizer que os indivíduos retratados nas distopias literárias puderam fazer parte de um social ao mesmo tempo real e irreal, não separado, mais imbricado na tecnologia e na cultura informacional veiculada aos computadores e aos nãolugares.

Gibson notabilizou o termo ciberespaço, que acabou por tornar-se sinônimo de Internet, ou ambientes online. Nesse sentido, pode-se dizer que a figura do hacker ${ }^{6}$, que está sempre buscando algo e ao mesmo tempo fugindo da realidade, tem no mundo virtual o seu território, podendo assim, ser entendida como a representação atual do que Baudelaire havia percebido no século XIX nas figuras perdidas nas multidões das grandes cidades.

A especialista em literatura cyberpunk e cibercultura, Adriana Amaral, propõe a seguinte reflexão sobre obras literárias como Neuromancer:

No recém-nascido, obscuro e transdisciplinar campo da cibercultura, a inegável e inseparável relação cultura e tecnologia, e as próprias representações da tecnologia em todos os formatos midiáticos da cultura contemporânea, em suas interfaces com as teorias literárias e culturais pós-modernas, são compreendidas como as redes de conexão entre humanos e máquinas (Amaral, 2016, p.314).

Obras como Neuromancer e Snow Crash inserem-se dentro de uma forma de ficção científica social, o que o cinema faz muito uso, vide a distopia Her, em que a sociedade já

\footnotetext{
${ }^{4}$ Junção das palavras cybernetic e punk, indicando dessa forma uma fusão entre um ideal tecnológico e um estilo de vida fora dos padrões sociais, carregando uma forte carga niilista como forma de descrição da realidade.

${ }^{5}$ Nós de Yevgueny Zamyatin, Admirável Mundo Novo de Aldous Huxley e 1984 de George Orwell, por exemplo.

${ }^{6}$ São indivíduos com habilidades e altos conhecimentos de manipulação de dispositivos informáticos, esse termo na linguagem comum online remete a um tipo de pirata de Internet, pronto para quebrar sistemas e acessar dados proibidos (papel esse que seria relegado ao cracker).
} 
consegue dar conta do indivíduo por exatamente ter dado tudo ao indivíduo, criando dessa forma uma relação incompleta. Dessa forma:

Em vez de descrever e acreditar num mundo perfeito, um paraíso tecnológico, como computadores garantindo o bem-estar e ajudando na resolução de problemas das pessoas. Neuromancer nos aponta o lado negro que os avanços podem ocasionar megacorporações substituindo a soberania dos governos, trazendo toda a sorte de corrupção, aniquilação social e das relações interpessoais (Amaral, 2016, p. 315).

Para analisarmos sociologicamente a Internet, e as redes sociais virtuais em seu contexto, devemos percebê-la enquanto lugar situado em um espaço, desse modo, nossa tarefa impõe a necessidade de uma separação do que seria o real e o irreal (ou virtual). A discussão sobre a virtualidade na sociedade tecnológica fundou-se de forma mais marcante a partir das décadas de 1990, com autores como Manuel Castells (2003) e Pierre Lévy (2011).

Castells percebeu identificou esse momento histórico como informacionalismo, que estaria:

(...) ligado ao rejuvenescimento do capitalismo, como o industrialismo estava ligado a sua constituição como modo de produção. (...) Embora a reestruturação do capitalismo e a difusão do informacionalismo fossem processos inseparáveis em escala global, as sociedades agiram/reagiram a esses processos de formas diferentes, conforme a especificidade de sua história, cultura e instituições. (Castells, 2012, pgs. 55-56)

No início da década de 1990, o cientista e empresário norte-americano do ramo digital, Nicholas Negroponte (1995) conclamou que vivíamos um monto chamado de digital e como Miskolci escreveu, sua percepção foi visionária, visto que trouxe essa ideia de mundo "digital" antes da real percepção social de produção e consumo, e do que significaria esse termo que seria percebido de fato apenas com a expansão das telecomunicações e da telefonia móvel.

Assim, precisamos entender: o que seria esse digital? Miskolci tenta esclarecer:

Digital, nesse sentido, não é uma definição técnica e, sim, uma caracterização de nosso mundo como marcado pela conexão por meio de tecnologias comunicacionais contemporâneas que se definem cotidianamente como digitais e atualmente envolvem o suporte material de equipamentos (como notebooks, tablets e smartphones), diferentes tipos de acesso (banda larga fixa ou celular), conteúdos compartilháveis (frequentemente gerados em outras mídias como jornais, revistas e televisão) e, por fim, mas não por menos, plataformas online (como Facebook, Twitter, Youtube). (Miskolci, 2016, p.283). 
A sociedade, então, com o avanço dessa caracterização digital, pode ser vista como uma "sociedade digital", devido a massificação e a aceitação dos dispositivos tecnológicos que tornaram mais fáceis inúmeras formas de contato social etc. A esse respeito, Crary, faz o seguinte comentário sobre a era digital:

É claro que ninguém pode fazer compras, jogar games, trabalhar, escrever em seu blog, fazer downloads ou enviar mensagens de texto 24/7. No entanto, uma vez que não existe momento, lugar ou situação no qual não podemos fazer compras, consumir ou explorar recursos em rede, o não tempo de 24/7 se insinua incessantemente em todos os aspectos da vida social e pessoal. Já não existem, por exemplo, circunstâncias que não podem ser gravadas ou arquivadas na forma de imagens ou informações digitais (Crary, 2014, p.40).

A partir da ideia da rapidez do mundo do 24/7 de Crary, temos o FOMO ou Fear of missing out é um termo cunhado recentemente ${ }^{7}$, aludindo ao medo de deixar passar imagens e assuntos divulgados em plataformas online de informação e em redes sociais virtuais. $\mathrm{O}$ FOMO produziria uma espécie de vício por informação, não importando a natureza ou a veracidade dos fatos disponibilizados.

Assim como o relógio assumiu um papel regulador nas sociedades modernas, temos na simbologia que antes era delegada às horas uma troca por segundos, sendo a rapidez uma maneira de tornar as relações mais atraentes. $\mathrm{Na}$ sociedade digital, os indivíduos reconfiguraram o tempo de seu dia a partir de uma nova percepção de tempo e espaço. A esse respeito, Miskolci suscita a imagem de um dia a dia possível:

\begin{abstract}
Em uma manhã de 2016, um sociólogo acorda com o despertador de seu smartphone. Ao desligá-lo, se depara com as atualizações na tela do equipamento. Durante a rotina matinal, começa a ouvir os sons da chegada de e-mails e mensagens instantâneas até que se senta diante do computador portátil e o liga, dando início a um novo dia de trabalho. Ao abrir o navegador para responder e-mails, também abre, na aba de trás, uma rede social que usa para divulgar pesquisas de sua área. Divide atenção entre os correios eletrônicos, as mensagens no smartphone, as da rede social, assim, como lê notícias nos sites dos principais jornais (Miskolci, 2016, p.276).
\end{abstract}

O tempo parece passar muito mais rápido quando estamos conectados, quem nos últimos anos não teve essa sensação, a velocidade da informação parece influenciar uma nova percepção temporal nos usuários de Internet e principalmente de redes sociais virtuais.

Em um futuro próximo, a tendência parece ser a de que a percepção dos indivíduos para com os dispositivos informacionais será de uma dependência cada vez maior e isso pode

\footnotetext{
7 Ver: http://i-d.vice.com/en_us/article/researchers-have-discovered-which-social-media-platform-is-the-worstfor-your-mental-health.
} 
tornar as relações humanas ainda mais distanciadas. A despeito das promessas de uma vida confortável, surge um problema central do debate que propomos aqui: como se configurarão as relações pessoais nesse mundo digital perfeito?

Assim com Her, temos a afirmação de um modelo social em que a tecnologia de fato venceu a sociedade, em que os indivíduos vivem uma vida em metrópoles acessíveis por trens transoceânicos e super velozes, em que as relações de trabalho não são exploratórias nem cansativas, entretanto, a lacuna das relações humanas fica em aberto, como percebemos.

O protagonista Theodore em uma das cenas iniciais, quando encontra-se dentro de um desses velozes metrôs metropolitanos, está de pé, recém-saído de seu trabalho não cansativo. Ele busca acessar um perfil hiperssexualizado de uma bela grávida em uma espécie de aplicativo de "vazamento" de fotos, ele fica excitado com o que vê. A tecnologia da exposição e da vigilância são mostradas em suas faces mais consumistas.

A beleza vista como uma forma de consumo ou um objeto, dentro da sociedade informacional - ou pós-moderna - serve de um exemplo contido no contexto daquilo que Bauman (1998) chamou de "modernidade liquida", isto é, um sujeito só é (pode ser) percebido através da posse de outros sujeitos (objetos) e do acesso que disso provém.

Ao consumir a imagem da bela grávida, Theodore se deixa levar pela beleza e pela sensualidade que nas redes sociais é uma latência, não importando questões tabu, como nesse caso, a exposição de uma grávida. Theodore é o retrato da solidão das grandes cidades, sua vida é uma rotina feita de lembranças e tristezas decorrentes de uma separação amorosa. $\mathrm{Na}$ parte inicial do filme sua vida resume-se a apresentar a solidão da sociedade tecnológica. Então querendo ter mais tempo para outras atividades de seu dia a dia, ele resolve comprar um software para gerenciar suas tarefas - por não ter tempo disponível - e percebe como esse dispositivo é muito eficiente, dessa forma, temos novamente a relação "natural" de dependência dos indivíduos para com a tecnologia.

O software ${ }^{8}$, que tem em uma voz feminina a sua interface, se mostra comunicativo e eficiente na gerência das tarefas informacionais, como também se mostra disposta a perguntar sobre a vida particular dele, sobre o trabalho, etc. A voz (ou Ela) por trás do software recebeu o nome de Samantha (a voz na dublagem original pertence a atriz Scarlett Johansson), que com sua delicadeza ao falar e a demonstração de interesse pelo que Theodore faz, acaba conquistando-o, fazendo com que a sua solidão seja momentaneamente por um dispositivo

\footnotetext{
${ }^{8}$ Software é um termo em inglês para programas de computador compostos de instruções para o gerenciamento de inúmeras tarefas e tendo como contraparte o termo Hardware, que significam as partes físicas do computador, como suas peças.
} 
tecnológico. Isso é o que podemos perceber no papel das redes sociais virtuais na vida de muitos indivíduos, a solidão das multidões, o estar perdido, os colocam em situações de vulnerabilidades, potencialmente sujeitos a manipulações.

As redes sociais seriam dispositivos de instrumentalização das relações sociais, pela tecnologia e pelo distanciamento, o que como percebemos, por intermédio da percepção do indivíduo dentro da modernidade, é que essa relação seria conflituosa e extremamente problemática por atrelar a exposição como forma de reciprocidade, gerando ao mesmo tempo um latente distanciamento da realidade, que afetaria os indivíduos em suas percepções de si, assim como vemos em Her.

Em outra cena de $\mathrm{Her}$, temos um exemplo mais elucidativo dessa problemática relativa ao deslocamento e também a questão da beleza, em que um corpo físico (uma jovem) é "alugada" para ser o corpo real da "voz", para assim, o personagem poder se relacionar sexualmente. O que provoca um estranhamento em Theodore, visto que a jovem não seria a imagem que ele faz de Samantha, percebemos nisso o que a rede social em nossos dias promove, por exemplo, vemos um perfil de alguém e esse mesmo alguém na realidade não se pareceria em nada com o que imaginamos (fantasiamos?).

A simulação entre uma voz computadorizada e uma pessoa real demonstra até quando a fantasia do deslocamento da realidade pode produzir uma relação problemática entre o ser e não ser, no caso de Theodore isso fica mais que evidente, a fantasia por trás da relação entre "homem" e "máquina" é o que a torna tão atraente.

Os indivíduos das redes sociais virtuais procuram fantasiar os corpos das pessoas com quem entram em contato online - não como sexo virtual - para obterem contrapontos reais dessas pessoas, colocando suas projeções sobre os outros, dessa forma, o ato de enganar que o Catfish promove é tão amplamente difundido. Para essa "realidade" buscada nos corpos e rostos belos é que se funda a natureza de enganação que o Catfish perpetra, o indivíduo quer obter fotos e vídeos de pessoas reais para ser sua ficha simbólica real, para suas futuras trocas com as vítimas, tornando sua imagem algo real.

A realidade (ou sua ideia) é o que funda o logro, a natureza por trás dos atos de extrair imagens reais de "pessoas reais", que para a contraparte, ou seja, para as vítimas parece ser aparentemente muito fácil acreditar em um perfil, já que se "conhecido" online bastaria comprovar a sua identidade com uma foto enviada.

A sociedade de Her não seria como a nossa, entretanto, carrega inúmeras similitudes com o que estamos vivenciando nos últimos anos, principalmente no que diz respeito aos relacionamentos mediados pelos computadores, ou seja, no papel das redes sociais virtuais, 
que dessa forma alteraram as formas sociais de produção de afetos, amizades, amor e desejos. Nas redes sociais virtuais, a beleza e o consumo desta são objetificados e massificados das formas, muitas vezes, bastante questionáveis, deixando assim brechas para o surgimento de distorções criminosas de realidade, como no caso dos Catfishes e de outros indivíduos que agenciam desejos.

\section{A sociedade digital: o homo panopticus e o nascimento do Catfish}

Com a sociedade digital, mais especificamente com o surgimento da Internet e das redes sociais, os corpos passaram a fazer parte do social de outras formas, uma delas, seria chamando atenção pela beleza, em função principalmente de um consumo acerca das "formas de beleza" que a mídia de massa potencializou ao longo do século XX.

A sociedade do presente parece ter sido alterada por novas formas de interação, que pressupõem aproximações via mecanismos digitais, e o estudo sociológico para entender esse consumo de beleza precisa deter-se nesses novos mecanismos surgidos.

Como afirmou Miskolci:

A sociedade digital convida a sociologia a rearticular suas teorias e conceitos sobre o social, os quais passam a ser repensados a partir de um contexto sobre em que as relações passam a ser cada vez mais mediadas e moldadas pela exposição intensificada às mídias (Miskolci, 2016, p.277).

A vigilância e a exposição seriam dois dispositivos centrais para o esforço sociológico de compreensão do impacto do "mundo digital" sobre a vida dos indivíduos.

Como vimos, o panóptico de Bentham tinha a pretensão de ser um dispositivo onisciente de vigilância. A vigilância sobre a sociedade seria o meio de controle. $\mathrm{O}$ que podemos perceber nos dias atuais em muitas das ruas das grandes cidades com suas câmeras e sensores de movimento que em qualquer lugar podem ser percebidos por meios digitais, sejam em centrais de monitoramento, seja no sofá de casa.

Como percebeu Miller acerca deste olhar quase divino:

Que o olho veja, sem ser visto - aí está o maior ardil do Panóptico. Se posso discernir o olhar que me espia, domino a vigilância, eu a espio também, aprendo suas intermitências, seus deslizes, estudo suas regularidades, posso despistá-la. Se o Olho está escondido, ele me olha, ainda que não esteja me vendo. Ao se esconder na sombra, o Olho intensifica todos os seus poderes - e a economia ainda ganha com isso, pois o número dos que suportam a função de vigilância pode ser reduzido na medida dessa intensificação (Miller, 2008, p.91). 
Na obra clássica de George Orwell ${ }^{9}$, 1984, lançada na década de 1940, temos o exemplo de um Estado totalitário, em que a figura do Big Brother desempenhava esse papel de olho que tudo vê, quase um deus. O Big Brother ou o Grande Irmão é uma crítica aos Estados totalitários, nessa distopia, o indivíduo é vigiado em todos os seus passos pela sociedade. A sentença: “O grande Irmão está de Olho em você” sintetiza essa pretensão de "divindade onisciente".

$\mathrm{Na}$ narrativa literária de Orwell, os indivíduos aparecem como figuras apagadas desempenhando suas funções de modo quase que autômato, como os robota do escritor tcheco Karel Capek $^{10}$, em que não importavam suas ações individuais, o que tinha relevância era sua capacidade de servir e de ser leal ao Grande Irmão.

As redes sociais virtuais firmam-se como dispositivos que propõem uma forma de interação mediante beleza (ou o que é belo), através da exposição constante de imagens e vídeos, que seria uma espécie de fidelidade a um Grande Irmão. O indivíduo "perdido" dentro dessa lógica de ser visto e consumido acabaria por aceitar a troca de sua intimidade pela exposição, abdicando muitas vezes de sua autonomia, submetendo-se assim à tecnologia.

A vigilância na Internet apresenta-se de forma potencializada pela via das redes sociais, atuando como dispositivo de um poder sem um fulcro central que provém e irradia-se de todos os lugares possíveis e atua no sentido de produzir um tipo de sujeito que precisa adaptar-se a ela, seja através da exposição ou através do controle de "todos os seus passos" na grande rede. As ferramentas tecnológicas aliadas a uma ideia de consumo rápido fizeram com o homo panopticus se tornasse real, um indivíduo ávido para consumir a exposição e a exporse, desejando ser visto, "curtido" e "seguido".

Mark Zuckerberg, principal fundador do Facebook, em suas palestras ao redor do mundo prega a igualdade através dos mecanismos de interação que constantemente os seus desenvolvedores procuram aprimorar, prometendo o fomento de uma comunidade global. Entretanto, de um ponto de vista sociológico, ao mesmo tempo que permite a aproximação de pessoas oriundas dos mais distintos lugares, também seria a forma de que todos pudessem ver todos, já que a interação é marcada pela exposição e não necessariamente há a necessidade de formação de laços de amizade - marca inicial do Facebook.

\footnotetext{
${ }^{9}$ Pseudônimo do escritor, ensaísta e jornalista Eric Arthur Blair (1903-1950).

${ }^{10}$ Escritor nascido em 1890 e morto em 1938, deixando além de um legado brilhante no campo da ficção científica, como as distopias "Na Guerra com as salamandras" e "Fábrica de Absoluto", uma peça de teatro que criticava ferozmente o regime soviético, a peça R.U.R, que apresentou o termo Robota, em eslavo significa escravo, e que depois foi amplamente difundido no ocidente como um variante de automato mecânicos, no caso, os robôs.
} 
O grupo que administra a rede social Facebook é o mesmo que controla outras duas redes sociais de caráter global: Instagram e WhatsApp, e somadas, todas elas somadas alcançam mais de dois bilhões de usuários. Essa relação de domínio acaba por desenvolver nesses indivíduos uma forma de dependência de informações filtradas por essas redes, em localidades afastadas dos grandes centros ocidentais milhões de usuários imaginam que o Facebook em si é a Internet, não conhecendo outra forma de acesso se não via rede social virtual.

O Facebook propõe aos seus usuários uma política de dados: "Concedemos a você o poder de compartilhar como parte da nossa missão de tornar o mundo mais aberto e conectado. Esta política descreve quais informações coletamos a como as utilizamos e compartilhamos ",11. Assim, o Facebook procura demonstrar que detém um poder sobre todas as suas ações online. Para tal, divide em tópicos e itens as formas de administrar essa vigilância, apresentados da seguinte maneira e na seguinte ordem: Quais as informações coletamos?; Como usamos essas informações?; Como estas informações são compartilhadas? Como faço para gerenciar ou excluir informações sobre mim? Como respondemos a solicitações judiciais ou evitamos danos? Como os nossos serviços globais operam? Como você será notificado sobre mudanças nesta política? Como entrar em contato com o Facebook em caso de dúvidas? ${ }^{12}$

Essas perguntas são respondidas em suas barras de informações, propondo de certa maneira uma clareza para os seus usuários, entretanto, esconde uma vigilância implícita, que acaba por ser aceita, visto que para fazer parte dessa rede social, há a necessidade de submeter-se a esses dispositivos. A vigilância dessa forma é um tipo de poder, aos moldes de Foucault, que estaria permeando todas as ações, disciplinando os indivíduos (usuários online) para se adequarem a uma "política de segurança".

$\mathrm{O}$ indivíduo imerso em redes sociais acaba por naturalizar os aspectos mais importantes da sociedade digital, que seriam a vigilância, a exposição e o controle de suas ações em ambientes virtuais, dessa maneira, o ato de expor sua vida não seria um problema e sim uma necessidade socialmente construída.

O homo panopticus deseja ser observado, ser consumido por meio da disponibilização de imagens, quer ser "curtido" e "seguido" em suas redes sociais virtuais e dessas suas necessidades surge uma questão: como obter essa visibilidade? Apenas expor-se não basta, há uma latência para consumir o que é disponibilizado, mas para tal há uma necessidade de

\footnotetext{
${ }^{11}$ Informações visíveis aos usuários do Facebook. Disponível em: http//www.facebook.com/privacy/explanation

12 Também disponível em: http//www.facebook.com/privacy/explanation
} 
pertença a uma rede social (ou todas). O Catfish é fruto dessa lógica de consumo virtual. Não à toa, o uso da beleza de "corpos belos" virtuais ou não é uma das estratégias do Catfish.

Para entendermos o homo panopticus, devemos recuar um pouco no tempo, chegando ao início dos anos 2000 para falarmos sobre os blogs, sendo uma antecessora das redes sociais no caráter de expor pensamentos, ideias e imagens, dando ao usuário da internet uma interface de interação em que sua vida pudesse ser exposta. O usuário de blog também poderia se articular e criticar a sociedade, aqui cabe uma referência a Pierre Lévy (2011) que percebeu na transparência dentro do ambiente virtual uma forma de resistência aos poderes instituídos.

Nas redes sociais, o universal não deve ser encarado enquanto totalidade, na qual uma cibercultura global, propiciada pela massificação das redes via internet, tende a promover uma interconexão generalizada, um movimento gerador de múltiplas formas de comunicação, mas sim, entendida, deixando de lado os aspectos econômicos e industriais, sob um prisma de formação cultural, que seria o de funcionar como um meio de abreviação de espaços, um gerador de laços e formador de opiniões (Lévy, 2011).

A Internet por abreviar espaços tendeu a promover aproximações, nela as distâncias físicas não seriam quase irrelevantes para seus usuários, qualquer lugar pode ser potencialmente alcançado, assim, com a massificação de um modelo de Internet, chamada de 2.0, que surgiu em 2004, no qual comunidades, serviços e a Web passaram a ter uma plataforma que possibilitou uma nova forma de navegação, mais fácil e ainda mais tecnológica. Essa segunda geração de Internet abriu caminho para os blogs, as redes sociais e as outras tantas formas de tecnologia de informação que vemos presentes em nossa sociedade atual, como os aplicativos de smartphones, por exemplo. Como percebeu Miskolci:

A chamada Internet 2.0 tornou possível o sucesso de plataformas que conhecemos como redes sociais, como o antigo Orkut $^{13}$ e o atual Facebook. Além dessas melhorias na rede, na qualidade e velocidade, no barateamento de equipamentos, dois outros fatores articulados e indissociáveis permitiriam que a rede alcançasse a maior parte da população brasileira em 2014: o crescimento econômico baseado na inserção das classes populares no universo do consumo, o que disseminou a telefonia celular com acesso à rede entre os mais pobres (Miskolci, 2016, p.281).

Nessa nova guinada informacional trazida pela Internet 2.0 é que podemos inserir nosso problema dos agenciadores de desejos em redes sociais virtuais e mais especificamente o Catfish.

\footnotetext{
${ }^{13}$ Rede social norte americana lançada em 2004, tendo sucesso principalmente em países populosos como Índia e Brasil. Deve seu nome ao engenheiro de computação do Google, o turco Orkut Büyükkökten, tendo sido extinta em 2014 devido ao sucesso absoluto do Facebook como rede social.
} 
A palavra Catfish ficou popular nos meios digitais a partir do lançamento do documentário de mesmo nome em $2010^{14}$, dirigido por Henry Joost e Ariel Schulman, que filmaram a trajetória de Nev Schulman (irmão do diretor) em busca de uma pessoa que conheceu no Facebook. No documentário são mostradas as artimanhas por trás da enganação, como principalmente os meios de atrair "vítimas", seja com trocas de músicas que a pessoa gosta (como no citado documentário) ou com fotos, que é a prática que aqui nos propomos analisar.

Nas redes sociais virtuais de alcance global ${ }^{15}$ uma das formas de interação gestadas foi a da produção de amizades, o que acaba promovendo mudanças na significação desse tipo de relação afetiva, pois a proximidade não se faz necessária, já que uma pessoa pode ser amiga de uma outra em qualquer lugar do mundo. E como tudo é tão rápido na sociedade digital, essa forma de produzir amizades parece ter se tornado insuficiente, assim, surgiu uma necessidade de adaptação e de reafirmação, que seria a produção de desejos.

$\mathrm{O}$ ato de produzir desejos requer "dispositivos desejantes", e no caso das redes sociais, para atrair atenção de possíveis novos amigos, percebemos a utilização da beleza como mecanismo de interação social. Desse modo, constitui-se da mesma forma como um "objeto desejado" para ser consumido. Como Deleuze (1994) delimitou, o agenciamento de desejos marca que desejo jamais é uma determinação "natural”, nem “espontânea”, a esse respeito, ele diz:

De minha parte, diria que o desejo circula nesse agenciamento de heterogêneos, nessa espécie de "simbiose": o desejo une-se a um agenciamento determinado: a um co-funcionamento. Seguramente, um agenciamento de desejo comportará dispositivos de poder (...), mas será preciso situá-lo entre os diferentes componentes do agenciamento (Deleuze, 1994).

Nas redes sociais percebemos no Catfish uma necessidade latente de criar desejos, sendo através do uso da beleza ou até mesmo dos padrões que cercam as belezas socialmente construídas, tornando essa "produção" heterogênea ao mesmo tempo que a faz caminhar junto da vítima como uma necessidade de consumo, de extrair afeto e amor desse poder sedutor da beleza agenciada. Desse modo, os agenciamentos de desejo não precisam de repressão

\footnotetext{
${ }^{14}$ Tendo depois do sucesso do documentário se tornado uma série da MTV norte americana em 2012 (também exibido pela MTV Brasil no mesmo ano), onde Nev Schulman e Max Joseph procuram desvendar casos reais de pessoas enganadas pelos Catfish.

${ }^{15}$ Existem redes sociais virtuais que se restringem a localidades específicas, devido a mecanismos de censura, como na Rússia com a $V K$, Vkontakte, tendo como slogan, ser uma forma universal de procurar pessoas, já na China com Sina Weibo, que seria uma fusão de Facebook e Twitter, percebemos que esses dois exemplos se mostram relevantes devido ao potencial populacional desses dois países que comportam, ou seja, em torno de $25 \%$ da humanidade.
} 
(Deleuze, 1994), apenas existem e são produzidos a todo momento. Ainda com Deleuze (1994) “o desejo não comporta qualquer falta. Ele não é um dado natural. Está constantemente unido a um agenciamento que funciona. Em vez de ser estrutura ou gênese, ele é, contrariamente, processo. Em vez de ser sentimento, ele é, contrariamente, afeto".

Por sua vez, o psicanalista francês Jacques Lacan (1998), o desejo representa um significante que designa a falta do outro. Como percebe Nunes (2015), Lacan postula um desejo tão heterogêneo às necessidades do corpo quanto diverso em sua demanda. Como efeito da submissão do corpo vivo à linguagem, o universo humano se institui em torno de um desejo que se revela ser o desejo de reconhecimento. Jacques-Alain Miller esclarece essa definição de Lacan: "um desejo evanescente, cujo único objeto e única satisfação é ser reconhecido pelo outro. Sem nenhuma substância, o que o dominaria, o enquadraria, o habitaria, seria o desejo de reconhecimento" |(Miller, 1999, p 40). E com Lacan:

Em parte alguma evidencia-se mais claramente que o desejo do homem encontra seu sentido no desejo de outro, não tanto porque o outro detenha as chaves do objeto desejado, mas porque seu primeiro objeto é ser reconhecido pelo outro (Lacan, $1953 / 1998$, p. 268)

O homo panopticus ao ser visto nas redes sociais acabaria por deixar uma lacuna aberta, que seria o papel que sua imagem representaria para os outros, a sua pretensa beleza como uma irrealidade, como um vício de si mesmo, ele participa e é aceito na produção de desejos sobre a sua imagem e a imagem dos outros. O homo panopticus quer ser reconhecido por todos, não importando como, seja com a verdade ou com a mentira, seja com a sua imagem ou a de outra pessoa. Dessa forma, as redes sociais, fazendo uma analogia, seriam como um teatro onde tudo é encenação, só que para o público que assiste seria a verdade, não percebendo que tudo o que vê é encenado, criado para manipular desejos.

A necessidade de atualização de seu (s) perfil (ou perfis) denota uma necessidade de tempo, de seu dia a dia, trabalho, estudo, etc, que acabam por torná-lo cada vez mais dependente de sua própria imagem, como no mito de Narciso, que a partir do reconhecimento de sua beleza não consegue prestar atenção em nada mais que o cerca.

Existe também uma outra lacuna nessa interação dependente, que podemos observar nos chamados Stalkers ${ }^{16}$, que buscam perseguir, intimidar, chantagear e acossar através de uma constante vigilância de determinadas pessoas, sendo celebridades, artistas ou pessoas

\footnotetext{
${ }^{16}$ Stalking ou cyberstalking, termos em inglês para perseguidor ou espreitar, expressão que surgiu na década de 1980 em função de indivíduos que perseguiam celebridades, hoje em dia acabou por ser correntemente usada para descrever perseguidores em mecanismos virtuais.
} 
comuns. Para esses indivíduos stalkers foram criadas leis como a Lei 12.237/2012 ${ }^{17}$, conhecida como "Lei Carolina Dieckmann”, que ficou conhecida por esse nome em razão da atriz de televisão Carolina Dieckmann que teve fotos e vídeos íntimos extraídos ilegalmente de seu dispositivo informático por um stalker, vindo a sofrer uma tentativa de chantagem por parte desse perseguidor.

A partir dessa e de outras leis, surgidas nos últimos anos, que visam punição como medidas restritivas, podemos perceber que a Internet mostra-se como um ambiente também dominado por práticas criminosas, no entanto é difícil rastrear as ações desses criminosos na Internet, visto sua potencialidade de ser um não-lugar. Como vivemos em uma sociedade que prega a exposição como forma de interação, esses stalkers acabariam por facilmente agir escondidos, vivendo dessa forma a margem de leis, tendo possibilidades múltiplas de ação, um pouco como os personagens da literatura cyberpunk.

A sociedade do século XXI é moderna de um jeito diferente, não havendo limites para o que o homem pode fazer e desfazer (Bauman, 1999), assim, podemos perceber a eterna busca de algo, que pode ser tanto dinheiro como relações pessoais. Nas redes sociais virtuais, com sua proposta de meio de comunicação de alcance global, capaz de permitir formar amizades independentemente das distâncias, temos o desenvolvimento de relacionamentos fragilizados, que podem esconder intenções não perceptíveis à primeira vista.

Ainda sobre a possibilidade de não sabermos "quem de fato é quem" nas redes sociais virtuais, temos o célebre cartoon de autoria de Peter Steiner, lançado no dia 5 de julho de 1993, na revista norte-americana The New Yorker, em que um cachorro sentado em uma cadeira na frente de um computador, com as patas dianteiras sobre o teclado (como se estivesse usando) fala para um outro cachorro: "Na Internet ninguém sabe que você é um cachorro" ${ }^{\prime 18}$. Isso seria uma incrível antevisão do que se tornariam as redes sociais, um lugar no qual não se pode saber exatamente com quem de fato se está conversando e trocando informações.

\footnotetext{
${ }^{17}$ Disponível em: http://www.planalto.gov.br/ccivil_03/_ato2011-2014/2012/lei/112737.htm

${ }^{18}$ No original, On the Internet, nobody knows you're a dog, lançada na The New Yorker de 5 de julho de 1993, tendo sido desenhada por Peter Steiner.
} 


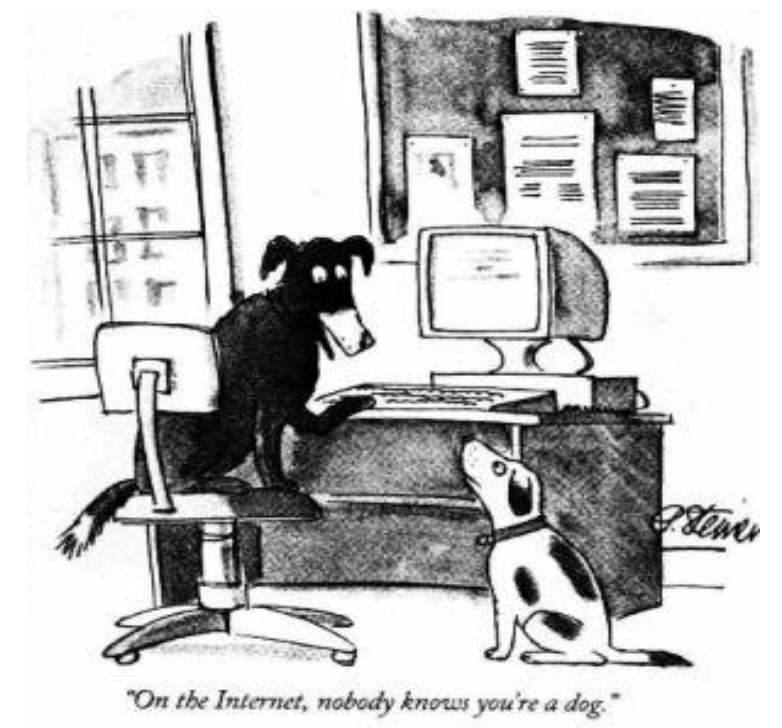

On the Internet, nobody knows you're a dog. Fonte: Wikipédia.

\section{Considerações finais}

A literatura sempre foi uma ótima maneira de percebermos as mudanças sociais, seja ela em qual esfera de ação representada - e podem ser muitas. Dessa forma, ao apresentarmos uma ideia de deslocamento de relações sociais, presentes em obras de ficção científica, como a literatura cyberpunk, propomos uma abordagem dessas temáticas que buscam apresentar a sociedade como um momento e um contexto conflituoso, em que a tecnologia seria o ingrediente de ação e ao mesmo tempo motivadora de revoluções e causadora de problemas aos indivíduos.

Os indivíduos, inseridos em um mundo em constante mudança, precisam buscar formas de adaptação para relacionar-se de uma forma melhor, para buscar, por exemplo, seu "lugar" na sociedade.

A sociedade tecnológica, que aqui apresentamos de forma breve, teve em seus desdobramentos, principalmente a era informacional, e em seu mecanismo de fácil propagação nas sociedades atuais, meios de fixar-se como propagadora de um constante controle mediado pela tecnologia em suas múltiplas interfaces.

As redes sociais virtuais e o advento da Internet, principalmente a chamada Internet 2.0 dos anos 2000, nos legaram uma nova forma de interação que não vê espaço como problema, estando em tudo e sendo permeada por tudo. Assim, ao trazermos os perfis falsos, ou os Catfish, buscamos olhar os problemas presentes nas redes sociais virtuais, como a necessidade de exposição e a dependência de conectividade, que trazem aos indivíduos momentos constantes de fragilidades. Nessa forma de interação pela exposição, surgem as 
vítimas enganadas pelos falsários, sendo que o papel de "vítima” pode ser dual, já que qualquer um poderia ser enganado ou até mesmo enganar. Tudo isso sendo possibilitado pelo caráter que as redes sociais virtuais portam, ou seja, de não serem rastreáveis.

A nossa ideia de trazer o homo panopticus como o exemplo desse indivíduo que quer ver e ser visto a todo momento, sendo indivíduo e não indivíduo ao mesmo tempo, poderia ser a melhor forma de mostrarmos essa ideia de potencial vítima dos Catfishes.

\section{Referências}

AMARAL, Adriana. A potência do imaginário de Neuromancer nas origens da cibercultura. IN: GIBSON, William. Neuromancer. São Paulo: Aleph, 2016.

AMARAL, Adriana. Visões Perigosas: uma arque-genealogia do cyberpunk. Porto Alegre/RS: Sulina, 2006.

ANDERSON, Perry. As origens da pós-modernidade. Rio de Janeiro: Jorge Zahar, 1999.

BAUMAN, Zygmunt. O mal-estar da Pós-modernidade. Rio de Janeiro: Jorge Zahar, 1998.

BAUMAN, Zygmunt. Globalização: as consequências humanas. Rio de Janeiro: Jorge Zahar, 1999.

BAUMAN, Zygmunt. Modernidade Líquida. Rio de Janeiro: Jorge Zahar, 2000.

BENJAMIN, Walter. Baudelaire e a Modernidade. Belo Horizonte/MG: Editora Autêntica, 2015.

BENTHAM, Jeremy. O Panóptico. Belo Horizonte/MG: Editora Autêntica, 2008.

BECK, Ulrich. Sociedade de risco. Rumo a uma outra modernidade. São Paulo: Editora $34,2011$.

BENDIX, Reinhard. A sociedade moderna. IN: PARSONS, Talcott (org). A Sociologia Americana. São Paulo: Cultrix, 1970.

CASTELLS, Manuel. A sociedade em rede (A era da informação: economia, sociedade e cultura, v.1). São Paulo: Editora Paz e Terra, 1999.

CASTELLS. Manuel. A galáxia da Internet: reflexões sobre a internet, os negócios e a sociedade. Rio de Janeiro: Jorge Zahar Editor, 2003.

CRARY, Jonathan. 24/7. Capitalismo e os fins do sono. São Paulo: Cosac Naify, 2014.

COSTA, Rogério da. Sociedade de Controle. São Paulo em Perspectiva, 18(1): 161-167, 2004. 
DEleuZE, Gilles. GUATTARI, Félix. O Anti-Édipo: Capitalismo e Esquizofrenia. São Paulo: Ed.34, 2010.

DELEUZE, Gilles. Désir e plaisir. Magazine Littéraire. Paris, n. 325, oct, 1994, pp. 57-65. (Desejo e Prazer). Disponível em: espaço michel foucault - www.filoesco.unb.br/foucault.

DELEUZE, Gilles. Post-scriptum sobre a sociedade de controle. IN: DELEUZE, Gilles. Conversações 1972-1990. São Paulo: Editora 34, 1992.

DURKHEIM, Emile. As formas elementares da vida religiosa. São Paulo: Martins Fontes, 2003.

DURKHEIM, Emile. Da Divisão Social do Trabalho. São Paulo: Martins Fontes, 1999.

ECO, Umberto. A história da feiura. Rio de Janeiro: Record, 2014.

ELIAS, Norbert. O processo civilizador. Rio de Janeiro: Jorge Zahar Editor, 1993.

ELIAS, Norbert. A sociedade dos indivíduos. Rio de Janeiro: Jorge Zahar Editor, 1994.

FOUCAULT, Michel. Microfísica do poder. Rio de Janeiro: Edições Graal, 1979.

FOUCAULT, Michel. História da sexualidade: a vontade de saber. Rio de Janeiro: Graal, 1988. $152 \mathrm{p}$.

FOUCAULT, Michel. Vigiar e Punir. O nascimento da prisão. Petrópolis/RJ: Vozes, 2006.

FOUCAULT, Michel. Em defesa da sociedade. São Paulo: Martins Fontes, 2010.

GIBSON, William. Neuromancer. São Paulo: Aleph, 2016.

HUYSSEN, Andreas. Culturas do passado-presente. Modernismos, artes visuais, políticas de memória. Rio de Janeiro: Contraponto, 2014.

KERLINGER, Fred. Metodologia de Pesquisa em Ciências Sociais: um tratamento conceitual. São Paulo: EPU, 1980.

KITTLER, Friedrich. As mídias ópticas. São Paulo: Contraponto, 2016.

KOSELLECK, Reinhart. Crítica e Crise. Uma contribuição à patogênese do mundo burguês. Rio de Janeiro: Contraponto, 2015.

LACAN, Jacques. Escritos. Rio de Janeiro: Jorge Zahar, 1998.

LEGROS, Patrick, MONNEYRON, Frédréric, RENARD, Jean-Bruno, TACUSSEL, Patrick. Sociologia do Imaginário. Porto Alegre/RS: Sulina, 2014.

LÉVY, Pierre. Cibercultura. São Paulo: Editora 34, 2011. 
MACHADO, Roberto. Por uma genealogia do poder. IN: FOUCAULT, Michel. Microfísica do poder. Rio de Janeiro: Edições Graal, 1979.

MATHIESEN, Thomas. A sociedade espectadora: o "panóptico" de Michel Foucault revisitado. Margem, São Paulo, n.8, p.77-95, dez.1998.

MATHIESEN, Thomas. The viewer society: Michel Foucault "Panopticon" revisited. IN: Theoretical criminology: an international journal 1(2) pp. 215-232, London: Sage, 1997.

MENEZES, Estera M. SILVA, Edna Lúcia. Metodologia de pesquisa e elaboração de dissertação. Florianopólis/SC: UFSC, 2001.

MILLER, Jacques-Alain. A máquina panóptica de Jeremy Bentham. IN: BENTHAM, Jeremy. O panóptico. Belo Horizonte/MG: Editora Autêntica, 2008.

MILLER, Jacques-Alain. Lacan elucidado: palestras no Brasil. Rio de Janeiro: Jorge Zahar, 1999.

MISKOLSCI. Richard. Sociologia Digital: notas sobre pesquisa na era da conectividade. Contemporânea - Revista de Sociologia da UFSCar. v.6, n.2 p. 275-297. Jul-Dez. 2016.

MCLUHAN, Marshall. Os meios de comunicação como extensões do homem. São Paulo: Cultrix, 2006.

MOCELLIN, Alan. Simmel e Bauman: modernidade e individualização. Em Tese, Vol.4 n.1 (1), agosto-dezembro/2007, p.101-118 ISSN 1806-5023.

NUNES, Tiago Ribeiro. Lacan e a negatividade do desejo. Revista de Psicologia da USP 2015, volume 26, número 3, pp. 423-429.

ORWELL, George. 1984. São Paulo: Companhia das Letras, 2009.

POGREBINSCHI, Thamy. Foucault, para além do poder disciplinar e do biopoder. Lua Nova N.63, 2004.

QUÉAU, Philippe. O Tempo do Virtual. IN: PARENTE, André (org.) Imagem-Máquina. Rio de Janeiro: Editora 34, 1993. pp. 91-100.

REMY, Jean. Gran ciudad y pequeña ciudad: tensiones entre sociabilidad y estética en Simmel. IN: MARQUÉZ, Francisca (ed.) Las ciudades de Georg Simmel. Santiago do Chile: Ediciones Universidad Alberto Hurtado, 2012.

SANTOS, Claudinei Caetano dos. A ação do controle velado - do panóptico ao sinóptico. Revista eletrônica do instituto de filosofia - IF Science Institute. ISSN 1984-5804. Disponível em: www.institutodefilosofia.com.br.

SEELIE, Tod. Inside an abandoned Panopticon prison in Cuba. Disponível em: www.atlasobscura.com, acessado em junho de 2017. 
SERRES, Michel. Polegarzinha: uma nova forma de viver em harmonia, pensar as instituições, de ser e de saber. São Paulo: Bertrand Brasil, 2013.

SIBILIA, Paula. O homem pós-orgânico. Rio de Janeiro: Contraponto, 2015.

SILVA, M.P. e MOURA, C.B. Mídia e a figura do anormal na mira do sinóptico: a constituição discursiva de subjetividades femininas. Rev. Estud. Fem. [online]. 2008, vol.16, n.3, pp.841-855.

SIMMEL, Georg. Filosofia da moda e outros escritos. Lisboa: Textografia, 2008.

SIMMEL, Georg. As grandes cidades e a vida do espírito (1903). Mana, out-2005, vol. 11, n. 2, p.577-591.

SIMMEL, Georg. O dinheiro na cultura moderna. IN: SOUZA, Jessé e ÖELZE, Berthold. Simmel e a modernidade. Brasília: UnB. 1998. p.109-117.

SIMMEL, Georg. O indivíduo e a liberdade. IN: SOUZA, Jessé e ÖELZE, Berthold. Simmel e a modernidade. Brasília: UnB. 1998. p. 109-117.

SIMMEL, Georg. Questões fundamentais de sociologia. Rio de Janeiro: Jorge Zahar, 2006.

STEPHENSON, Neil. Snow Crash. São Paulo: Aleph, 2015.

VANDERBERGHE, Frédéric. As sociologias de Georg Simmel. Bauru: EDUSC, 2005.

VIRILIO, Paul. Estética da desaparição. Rio de Janeiro: Contraponto, 2016.

WAIZBORT. Leopoldo. As aventuras de Georg Simmel. São Paulo: Editora 34, 2006.

ZABLUDOVSKY K. Gina. El concepto de individualización en la sociologia clásica y contemporánea. Política y Cultura, núm. 39, 2013, pp. 229-248. Universidad Autónoma Metropolitana Unidad Xochimilco. DF, México. 